\title{
Ageing and Its Effect on Body-Self Image, Mood and Self Esteem of Middle Age Women and Older Women.
}

\author{
Dr. Pinky Goswami
}

\begin{abstract}
Ageing is an important part of all human societies reflecting not only the biological changes that occur, but also reflecting cultural and societal conventions. Chronological ageing may also be distinguished from 'social ageing' and 'biological ageing'. There is also a distinction between 'proximal ageing' (age-based effects of recent past) and 'distal ageing' (differences because of incidences early in life that can be traced back to a reason early in person's life like an early marriage, early pregnancy etc). In our youth-oriented, patriarchal society, aging women often find themselves either ignored, pitied, or feared which is why most women are very concerned with the ageing factor. The effect of ageing is seen more in middle age women because they are neither fully old nor are they young. They are still compromising with the fact that "age" is slipping out of their hands. Middle age is a phase of transition from young age to old age and this fact of finally accepting age is quite stressful for many. A post menopausal woman is often found to be more accepting to the fact of ageing, and more comfortable physically and emotionally. The present study is conducted to study the effect of Ageing on Body self image, mood and self esteem of middle age women and older women. A sample of 160 women in the age range of 45-55years and older women in the age range of 55-65years is taken .It is hypothesized that middle age women have low body self image, low mood and are low on self esteem. The research provides an insight into understanding women especially in her transition to an older woman; it further enables society to develop better mental as well as physical health reforms which are the need of the day for every single woman.
\end{abstract}

\section{Introduction}

Ageing is an inevitable phase of Human Life and yet very few feel elated to face it. Many a poet claims it to be the evening or sunset of life. Ageing is the physical, psychological and social change in a person over a period of time. One issue that has beset the development of research on aging is a definition of old age (Scanzoni \& Scanzoni, 1988). Research in the United Kingdom and the United States has found that the older a person is in a chronological sense, the later is the chronological age at which that person tends to think old age begins. The concept of old age also is affected by social stratum: middle class-status persons, as an example tend to think that old age begins after fifties, while higher-status persons tend to think that old age begins around age 65. It leaves none, whether rich or poor and higher class or lower class. Ageing comes with a sinking feeling which may be due to the fact that youth is snatched from our hands by destiny and it cannot be avoided. The phase of Ageing is an important part of all human societies reflecting not only the biological changes that occur, but also reflecting cultural and societal conventions. Age is measured chronologically, and a person's birthday is often an important event. Chronological ageing may also be distinguished from "social ageing" (cultural ageexpectations) and "biological ageing". There is also a distinction between "proximal ageing" (age-based effects of recent past) and "distal ageing" (differences because of causes early in life that can be traced back to a cause early in person's life like an early marriage, early pregnancy etc). Ageing is seen to impact women very differently from a man. In our youth-oriented, patriarchal society, aging women often find themselves either ignored, pitied, or feared which is why most women are very concerned with the ageing factor. Women are more dearly affected by ageing than man as beauty is attached to youth and as youth declines beauty also sets. After reaching the pinnacle of youth comes the middle age of women where they are neither fully old nor are they young. They are still compromising with the fact that "age" is slipping out of their hands.

Middle age is a phase of transition from young age to old age and the fact of finally accepting age is quite stressful for many. When a woman turns around 40, she can start to feel the physical changes that manifest in her body. This could be in terms of weight gain, loose skin, wrinkles in the face, skin pigmentation, loss of hair and even a few white hairs. This is greatly caused by menopausal reasons. As a woman ages she advances towards menopause and at this phase hormones are drastically being altered in her system. This phase is called the Pre-menopause, often referred to as perimenopause. It is the phase in a woman's life just before the onset of menopause, which is when a female's menstrual cycle permanently ceases. Menopause occurs 12 months after the last menstrual period. The average age for a woman to begin experiencing premenopausal symptoms is 45 , but women as young as 25 and as old as 70 can also exhibit signs of pre-menopause. The length of premenopause varies from woman to woman, but typically lasts from one to six years. 
During pre-menopause, a woman's hormone production begins fluctuating and declining, which can cause a wide variety of symptoms. A majority of premenopausal women experience changes in their menstrual cycle. As a woman's estrogen levels begin to decline, the menstrual cycle may shorten, causing more frequent periods. However, some women begin to have longer cycles and less frequent periods. Some women even skip periods. Despite these menstrual changes, a woman is not considered truly menopausal until she has had no period for twelve consecutive months.

In addition to menstrual cycle changes, the drop in estrogen levels during pre-menopause can cause a host of other physical symptoms, such as hot flashes, night sweats, weight gain, headaches, vaginal dryness, breast tenderness, and sleep problems. Pre-menopause can also trigger a variety of emotional changes; including anxiety, irritability, depression, and a sudden inability to handle stress These hormonal changes lead to a lot of impact on the psyche of a women. The period that follows after menopause is called post menopause.

But when a woman's body has adjusted itself to the changes of hormone level, she begins to feel at ease with herself. She feels less stressed and is able to actually count the progress she has made in her earlier years. She does not mind getting older anymore, as long as she remains healthy. The fact of ageing will seem less disturbing for her as she gets more accepting to the fact of her growing in age. She feels settled and also begins to enjoy life more fully.

But a trend seen today is that women after the age of 40 which marks the onset of middle age, leads life more fully and is often found to do things which she may have avoided in her youth. Many women who wore simpler clothes as a young girl is found to dress up in more gorgeous clothes. This behavior is getting prominent as today's women values herself and wants to enjoy the youth period entirely and is also found to find ways to postpone the phase of ageing. Women of all economic categories greatly relies on beauty products with full expectation of prolonging the phase of youth which is the reason behind a boom in the number of beauty products and Beauty salons in every nook and corner in India. They do not mind the expenditure with regards to prolonging the period of youth.

An older woman is more accepting to the fact of ageing as by 55 years a woman is past her menopause and are found to be more comfortable physically and emotionally. This phase is called the postmenopausal phase. Post-menopause is a time when most of the distress of the menopausal changes have faded. Hot flashes may seem milder or less frequent; energy and emotional levels may seem to have stabilized. It is generally believed by most clinicians that the post-menopausal phase begins when 12 full months have passed since the last menstrual period. Another typical guideline is to measure the level of the follicle stimulating hormone (FSH).Women with low levels of sexual desire, often as a result of menopause, are more likely to be depressed and to suffer physical symptoms such as back pain and memory problems than women who report higher levels of desire, according to a new study by researchers at the University of North Carolina at Chapel Hill and Procter \& Gamble Pharmaceuticals(2009)

The difference between a beautiful twenty year old and a beautiful fifty year old is that one shows the beauty of youth and the other shows the beauty of soul. Most interesting to note is that women who have the most problem with aging are the ones who were beautiful. Maybe it's because plain looking women have to make peace with their appearance at a much younger age. Women who have spent a lifetime being beautiful really seem to struggle with the approaching wrinkles and drooping body. It is difficult for them to accept that they are ageing and younger beautiful women are taking their place.

Some women choose to fight against aging, especially if one's sense of self worth is wrapped up in their looks. For some women, their entire sense of personal power comes from being visually appealing to others. That's not to say they sell themselves, but that there is a power that comes from looking incredibly beautiful. It's no secret that a beautiful smile can open doors.

Every year, people spend billions on beauty products, from vitamins to face creams, to stop aging. The worry in ageing is also about many things such as losing memory, teeth, eyesight, hearing, sex drive, and some special concerns about osteoporosis (thinning bones) and other age related disorders.

In a society that places much value on youth, a woman's body image can be affected by aging in many ways. Physical changes such as weight gain, hair loss, and wrinkles can affect a woman's self-esteem. Post Menopause carries its own bag of anxiety and worry. The most commonly seen problem in ageing besides losing youth is "Osteoporosis". Most Indian women suffer from Osteoporosis. It can lead to broken bones and fractures, affecting a woman's independence. Women can often have two stressful roles - as a caregiver and a caretaker - raising children and taking care of elderly parents. Women can also feel lonely and less useful as they age, leading to depression. Woman in India is like an anchor for the homes but as they age they are in a way replaced by the young daughter in laws, which sets in huge turmoil between the two generations. A mother in law and a daughter in law are mostly found to be at logger heads and this can be rooted down to the fact that it is not easy for a woman to accept that she is growing old and needs to retire thus handing over all decisive roles to her daughter in law. 
Body Self Image is how the physical appearance affects the image of self within. It is how one views one's physical self - including whether one feels that they are attractive and whether others like their looks. It is seen that woman who do not wrap beauty with self worth does not get much impacted with ageing as those whose self worth depends on the Body image. Bodily states are key markers manifesting the social definitions of the self, and the role. It is a powerful source for metaphor (Crawford 1984).

Biologically a body has to age but women all over the world are ready to put up a fight against this. Medical Science gives their support by coming up with the various researches to fight ageing by cosmetic surgery, various cosmetics etc etc. Within last thirty years plastic surgery has grown exponentially and has not yet revealed deceleration. This is enough to reveal that most women do feel that with ageing they are losing their sense of worth. Even women who are not beautiful may want to fight ageing because with ageing, not only wrinkles come in the package but also a number of age related disorders which may bring a women who has been self dependant to be a dependant on others. A woman as mentioned earlier works as the anchor of a house but ageing may shake her self worth as she sees a younger woman replacing her on the pretext of her ageing .She thus need to retire. In India, a mother looks forward to her son's marriage but at the same time a feeling of insecurity sweeps into her heart because of the thought of the daughter in law taking her position as the anchor of the house.

Around menopause, changes in the genital organs occur rapidly. Menstrual cycles stop, and the ovaries stop producing estrogen. After menopause, the tissues of the labia minora, clitoris, vagina, and urethra thins (atrophy). This thinning can result in chronic irritation, dryness, and a discharge from the vagina. Vaginal infections are more likely to develop. Also after menopause, the uterus, fallopian tubes, and ovaries become smaller. With aging, there is a decrease in the amount of muscle and connective tissue, including that in muscles, ligaments, and other tissues that support the bladder, uterus, vagina, and rectum. As a result, the affected organs may sag or drop down (prolapse), sometimes causing a feeling of pelvic pressure or fullness, difficulty urinating, loss of control of urination or bowel movements (incontinence), or pain during sexual intercourse. Women who have had many children are more likely to have such problems. Because there is less estrogen to stimulate milk ducts, the breasts decrease in size and may sag. The connective tissue that supports the breasts also decreases, contributing to sagging. Fibrous tissue in the breasts is replaced with fat, making the breasts less firm.

These physical changes that occur with menopause may affect a persons body self image, moods depending on what level of self esteem an individual may possess.

Several studies have indicated that Asian women's experience of menopause is different and it affects them differently (Lock 2002).

It is also seen that despite these changes with menopause, many women enjoy sexual activity more after menopause, possibly because there are no chances of getting pregnant. In addition, after menopause, the ovaries and adrenal glands continue to produce male sex hormones. Male sex hormones help maintain the sex drive, slow the loss of muscle tissue, and contribute to an overall sense of well-being. Women have been reported to appreciate menopause in developing countries and especially in India (Flint and Samil 1990; Singh and Arora 2005; Gupta et al. 2006).

Mood swing, also known as mood disorder, refers to a condition when a woman experiences and expresses a gamut of emotions within a span of a few hours. The moods range from happiness to anger, frustration, sadness to depressive psychosis, all within a very short period of time. However mood swings should not be construed as so severe or long lasting as other depressed and manic states of bipolar disorder or manic depression.

A woman with mood swings is like a roller coaster; she is up one minute and down the next and never able to get off the ride that easily. Mood swings are as such unpredictable and often disproportionate to the situation. The moods feel uncontrollable. Periods of intense elevation are followed by severe depression. Sleep patterns stand disrupted.

The problem of mood swings is common with women in metropolitan cities with higher work pressure, speedier life style and lower levels of patience. Certain physiological and emotional factors contribute to such mood swings.

Hormonal imbalance, chemical imbalances, menopause, pregnancy, hypothyroidism, endocrine abnormality and other such biological/physiological problems are some leading factors for fluctuating moods in women. Menopause is a time when changes in hormones such as estrogen, testosterone and progesterone occur. At the time of ovulation some women experience a lot of behavioral, emotional and physical changes, all due to hormonal variations.

The human brain releases chemicals called neurotransmitters which cause myriad feelings such as happiness, stress, fear, depression and anxiety and so on. Imbalance of the neurotransmitters serotonin, norepenephrine, dopamine and GABA contribute to mood swings. Perimenopause is the time when the body does not have enough support to maintain its natural balance. This is the time in life when in many women could 
experience a resurfacing of old emotional issues that remain unresolved. Mood swings and irritability could be a part of the emotional make up at this juncture in life..

Self-esteem is all about how much you feel you are worth - and how much you feel other people value you. Self-esteem is important because feeling good about yourself can affect your mental health and how you behave. People with high self-esteem know themselves well. They're realistic and find friends that like and appreciate them for who they are. People with high self-esteem usually feel more in control of their lives and know their own strengths and weaknesses. Many Indian Woman believe that monthly menstrual bleeding would clean their body of 'dirty blood'. As this process was discontinued at menopause they believed that they have grown physically weak, lost interest and enthusiasm. They felt that their importance had decreased and that they were of no use. This was an indirect remark about the reduced sexuality and attractiveness. Thus many times they associated menopause with loss of femininity. This was further thought to be interfering with their confidence and self-image and self-esteem. Decreased physical capacity, loss of interest from social life, loss of sexual interests, loss of stamina, feeling of being old, feeling depressed was associated with menopause. (Arti Kaulagar ,"Menopause and Femininity: Qualitative Enquiry into Menopause of Urban Women from Pune, Maharashtra 2010).Depending on the individual, the tradition of handing over the house by a elder lady to a younger lady to an extent may impact the self esteem of the ageing women if they have attached self esteem to being an authority figure in the house hold activities.

It is also seen that many woman attaches self esteem to their Body image which is associated with beauty ,femininity and youth so with growing age as beauty diminishes many a woman find their self worth low and thus giving rise to a low self esteem.

\section{Defining Ageing In India}

In ancient India, life span of one hundred years was divided into four stages: life of a student, householder, forest dweller and ascetic. There was a gradual move from personal, social to spiritual preoccupations with age. People above 60 years of age were considered as 'old' and as constituting the 'elderly' segment of the population. In the traditional Indian culture, a human life span is one hundred years. Manu, the ancient law giver, in his Dharmasastra divided this span of life into four 'ashramas' or life stages. The first, " bramhacarya' (life of a student) was to be spent at the teacher's (guru) house. This is the life of a celibate, to be spent in education and training. Once education was complete, the boy (grown into adulthood by now) would be ready to enter the ' grihasta' ashram. This was the life of a householder. A man was to marry, have children, and shoulder the responsibilities of an average citizen in the society. He was to discharge the debts he owed to the parents (pitru rina) by begetting sons and to the Gods(deva rina) by performing Yajnas (rituals). This was the stage when a man would fulfill his basic desires, for love, marriage, for parenthood, for status, wealth, prestige and other such physical and social needs. When a man's hair turned grey and wrinkles appeared, he was to give up this life of a householder and turn to 'vanaprastha' which literally means 'moving to the forest'. A mature and ageing man would gradually give up his worldly pursuits, move away from the mundane routine of householder and turn towards spiritual growth. Finally, when he is spiritually ready, he would renounce the world completely and enter the stage of 'sanyasa' or asceticism.

Though this scheme of a man's life did not comment about a woman's life, it was assumed that a wife would follow her husband faithfully in his move through different stages. So in India, a person would be considered old when his children were married and he had grandchildren, regardless of his chronological age. In Indian culture early marriage still quite common. Marriage of a son and arrival of a daughter-in-law into the joint family often marked a major transition in the life of a woman. She would usually hand over the responsibilities of the household and relinquish her own position as 'mistress' of the house. In some parts of India, married women usually would have the keys of the house tied to the end of their ' pallu' (part of the sari that is drawn up over the upper part of the body or head). When the bride arrived, these keys would be handed over to her symbolizing a transition in the status of the older woman. Menopause and arrival of grandchildren usually marked old age for women. There is a trend for women to consider themselves old at a younger age than men. This ageing process may impact the self esteem of an individual specially a women to a great extent.

\section{AIMS OF THE STUDY.}

1. There is a significant difference between the old age woman and middle age woman in terms of Body Self image, moods and self esteem.

2. The old age woman will have higher Body self image, moods and self esteem as compared to the middle age woman.

3. Body self image, moods and self esteem in both age group of woman will have a positive correlation. 


\section{Methodology}

SAMPLE: 160 subjects were taken as samples out of which 80 were middle age woman( age: 40-55) and 80 were old age woman (age 55-70).

DESIGN:

\begin{tabular}{|l|l|}
\hline \multicolumn{1}{|c|}{2 Age group } & \\
\hline Middle age & $\mathrm{N}=80$ \\
\hline Old Age & $\mathrm{N}=80$ \\
\hline
\end{tabular}

INDEPENDENT VARIABLE: 1 X 2 Factorial design was used

Ageing - 1

Age group - 2

DEPENDANT VARIABLE: Body Self Image, Moods, Self Esteem

CONSTANT VARIABLE: Only Premenopausal Woman taken as sample for middle age woman (age $=40 \mathrm{yrs}-$ 55yrs).

Post Menopausal woman taken as sample for old age woman (age $=55 \mathrm{yrs}-70 \mathrm{yrs})$.

All women were educated and belonged to middle class homes

STATISTICAL TREATMENT: ANOVA was used in the analyses of results. Further Parametric statistical measure of correlation have been used.

\section{TOOLS:}

1. MultiDimensional Body Self Relations Questionnaire (MBSRQ). It is a 69 item instrument by Thomas F.Cash, designed to measure self-attitudinal aspects of the body-image construct. It contains a number of subscales based on factor analysis: appearance evaluation, appearance orientation, fitness evaluation, fitness orientation, health evaluation, health orientation, illness orientation, body areas satisfaction, subjective weight and weight preoccupation. A total score was taken with high score implying higher body self image.The first seven factors have very good internal consistency with alphas that range from .75 to .90 . All subscales have good to excellent stability, with test-retest correlations that range from .49 to .91 . The MBSRQ has demonstrated its validity in numerous studies.

2. The Mood Survey (MS) is an instrument by Bill Underwood and William J.Froming which assesses happy and sad moods. A high score indicates happy moods and a low score indicates sad moods. Test-retest reliability over three weeks is .80 . The MS has good concurrent validity, correlating significantly with a number of other measures such as Beck Depression inventory and Mood adjective Checklist.

3. Self-Esteem Rating Scale (SERS) is a 40 item instrument developed by William R.Nugent and Janita W.Thomas provide a clinical measure of self- esteem that can indicate levels of self esteem. SERS has excellent internal consistency with an alpha of .97. It has good content and factorial validiy. It also has good construct validity with significant correlations with index of self esteem and the generalized contentment scale( a measure of depression) as predicted.

\section{PROCEDURE:}

The data was individually collected from 160 subjects, 80 middle age women (pre-menopausal woman of age 40yrs-55yrs) and 80 old age women (post menopausal women of age 55yrs-70yrs). Subjects were approached at their respective residences. A personal rapport was created with each woman. They were made to feel comfortable and warm. Thereafter they were given the 3 scales one by one to be completed. Necessary instructions were given. The scores thus obtained were subjected to statistical analysis relevant for factorial design.

\section{Results}

Table 1.1: Showing Mean and Standard deviation of body image, self esteem and mood survey in middle age women( pre-menopausal) and old age women( post menopausal ).

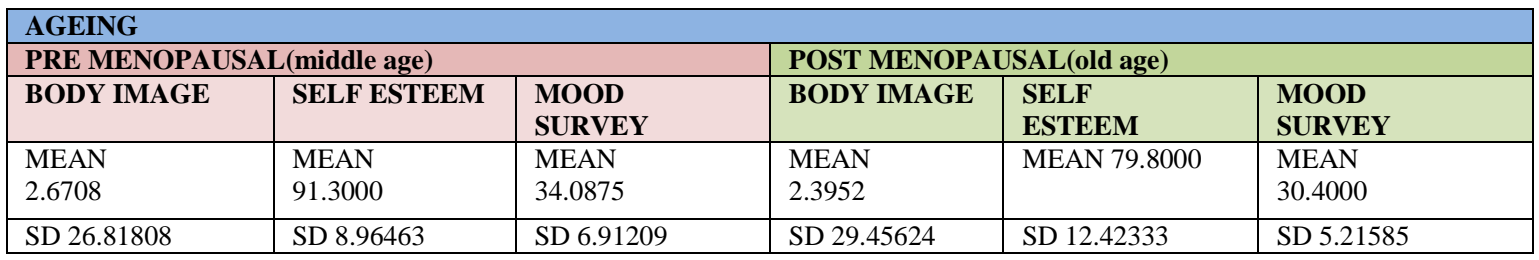


Table 1.2: Showing $t$ test of body image in middle-age women(pre-menopausal )and old age women( post menopausal).

\begin{tabular}{|l|l|l|l|l|l|}
\hline VARIABLE & COMPARISON & MEAN & SD & t & SIGNIFICANCE \\
\hline BODY IMAGE & $\begin{array}{l}\text { PRE } \\
\text { MENOPAUSE }\end{array}$ & 2.6708 & 26.81808 & -6.186 & $<0.01$ \\
\cline { 2 - 4 } & $\begin{array}{l}\text { POST } \\
\text { MENOPAUSE }\end{array}$ & 2.3952 & 29.45624 & & \\
& & & & \\
\hline
\end{tabular}

Pre-menopause: middle age

Post menopause: old age

A t test revealed significant level of difference in the mean of Body self image between the middle age woman (pre) and old age women (post). The mean of middle age women (pre) is (M=2.6708, SD =26.81808) and old age women(post) is $(\mathrm{M}=2.3952, \mathrm{SD}=26.81808), \mathrm{t}(158)=-6.186, \mathrm{p}=.000, \alpha=0.01$.

Table1.3: Showing $t$ test of mood survey in middle age women (pre-menopause) and old age women (post menopause).

\begin{tabular}{|l|l|l|l|c|l|}
\hline VARIABLE & COMPARISON & MEAN & SD & t & SIGNIFICANCE \\
\hline $\begin{array}{l}\text { MOOD } \\
\text { SURVEY }\end{array}$ & PRE MENOPAUSE & 34.0875 & 6.91209 & -3.809 & $<0.01$ \\
\cline { 2 - 4 } & POST MENOPAUSE & 30.4000 & 5.21585 & & \\
\hline
\end{tabular}

Pre-menopause: middle age

Post menopause: old age

A t test revealed significant level of difference in the mean of Mood Survey between the middle age woman (pre) and the old age women (post). The mean of middle age women (pre) is $(\mathrm{M}=34.0875, \mathrm{SD}=6.91209)$ and old age women (post) is $(\mathrm{M}=30.4000, \mathrm{SD}=5.21585), \mathrm{t}(158)=-3.809, \mathrm{p}=.000, \alpha=0.01$.

Table1.4: Showing $t$ test of self esteem in middle age women(pre-menopause) and old age women (post menopause)

\begin{tabular}{|l|l|l|l|r|l|}
\hline VARIABLE & COMPARISON & MEAN & SD & t & SIGNIFICANCE \\
\hline \multirow{3}{*}{ SELF ESTEEM } & PRE MENOPAUSE & 91.3000 & 8.96463 & -6.714 & $<0.01$ \\
\cline { 2 - 4 } & POST MENOPAUSE & 79.8000 & 12.42333 & & \\
& & & & & \\
\hline
\end{tabular}

Pre-menopause: middle age

Post menopause: old age

A $t$ test revealed significant level of difference in the mean of Self Esteem between the middle age women (pre) and the old age women (post). The mean of middle age women (pre) is (M=91.3000, SD =8.96463) and the old age women is $(\mathrm{M}=79.8000, \mathrm{SD}=12.42333), \mathrm{t}(158)=-6.714, \mathrm{p}=.000, \alpha=0.01$.

Table1.5: Showing one way ANOVA of mood survey, body image and self esteem in middle age women( pre-menopause)and old age women (post menopausal)

\begin{tabular}{|l|l|l|l|l|l|}
\hline $\begin{array}{l}\text { DEPENDENT } \\
\text { VARIABLE }\end{array}$ & $\begin{array}{l}\text { INDEPENDENT } \\
\text { VARIABLE }\end{array}$ & MEAN & STD.ERROR & F & SIGNIFICANCE \\
\hline \multirow{2}{*}{ MOOD SURVEY } & PRE MENOPAUSE & 34.0875 & .77280 & 14.508 & $<0.01$ \\
\cline { 2 - 5 } & POST MENOPAUSE & 30.4000 & .58315 & & \\
\hline \multirow{2}{*}{ SELF ESTEEM } & PRE MENOPAUSE & 91.3000 & 1.00228 & 45.078 & $<0.01$ \\
\cline { 2 - 5 } & POST MENOPAUSE & 79.8000 & 1.38897 & & \\
\hline \multirow{2}{*}{$\begin{array}{l}\text { BODY } \\
\text { IMAGE }\end{array}$} & PRE MENOPAUSE & 2.6708 & 2.99835 & 38.264 & $<0.01$ \\
\cline { 2 - 4 } & POST MENOPAUSE & 2.3952 & 3.29331 & & \\
\hline
\end{tabular}

Mood Level differed significantly between the middle age women( pre) and the old age women(post), F (1, 158) $=14.508, \mathrm{p}<0.01$. Women belonging to the middle age (pre) had higher mood levels with $(\mathrm{M}=34.0875)$ than women of old age (post)with $(\mathrm{M}=30.4000)$

The level Self Esteem differed significantly between middle age women (pre) and old age women (post). The middle age women (pre) had a higher self esteem with $(\mathrm{M}=91.3000)$ than old age women (post) with $(\mathrm{M}=79.8000)$ 
Body self image differed significantly between middle age women (pre) and old age women (post). The middle age women (pre) had a higher self esteem with $(\mathrm{M}=2.6708)$ than the old age women (post) with $(\mathrm{M}=2.3952)$

Table1.6: Showing correlation between mood survey, body image and self esteem in old age women (post menopause)

Correlations
\begin{tabular}{|ll|l|l|l|}
\hline & Mood Survey & Self esteem & Body Image \\
\hline $\begin{array}{llll}\text { Mood } \\
\text { Survey }\end{array}$ & Pearson Correlation & 1 & $.419^{* *}$ & .006 \\
& Sig. (2-tailed) & & .000 & .956 \\
& $\mathrm{~N}$ & 80 & 80 & 80 \\
\hline Self esteem & Pearson Correlation & $.419^{* *}$ & 1 & $.321^{* *}$ \\
& Sig. (2-tailed) & .000 & & .004 \\
& $\mathrm{~N}$ & 80 & 80 & 80 \\
\hline Body Image & Pearson Correlation & .006 & $.321^{* *}$ & 1 \\
& Sig. (2-tailed) & .956 & .004 & \\
& $\mathrm{~N}$ & 80 & 80 & 80 \\
\hline
\end{tabular}

**. Correlation is significant at the 0.01 level (2-tailed).

Mood level of old age women (post) shows a positive correlation with self esteem of old age women (post) at 0.01 level of significance. Self esteem of old age women (post) women also shows a positive correlation with Body image of old age women (post) at 0.01 level.

Table1.7 showing correlation between mood survey, body image and self esteem in middle age women( pre- menopause)

\begin{tabular}{|c|c|c|c|c|}
\hline \multicolumn{5}{|l|}{ Correlations } \\
\hline & & Mood survey & Self esteem & Body Image \\
\hline \multirow{3}{*}{$\begin{array}{l}\text { Mood } \\
\text { Survey }\end{array}$} & Pearson Correlation & 1 & -.195 & -.008 \\
\hline & Sig. (2-tailed) & & .083 & .945 \\
\hline & $\mathrm{N}$ & 80 & 80 & 80 \\
\hline \multirow[t]{3}{*}{ Self esteem } & Pearson Correlation & -.195 & 1 & .151 \\
\hline & Sig. (2-tailed) & .083 & & .180 \\
\hline & $\mathrm{N}$ & 80 & 80 & 80 \\
\hline \multirow[t]{3}{*}{ Body Image } & Pearson Correlation & -.008 & .151 & 1 \\
\hline & Sig. (2-tailed) & .945 & .180 & \\
\hline & $\mathrm{N}$ & 80 & 80 & 80 \\
\hline
\end{tabular}

No significant correlation was observed in middle age women (pre-menopausal) among Mood, Self esteem and Body Image.

Figure 1.1 :Showing mean of mood survey of middle age women( pre-menopause) and old age women( post menopause)

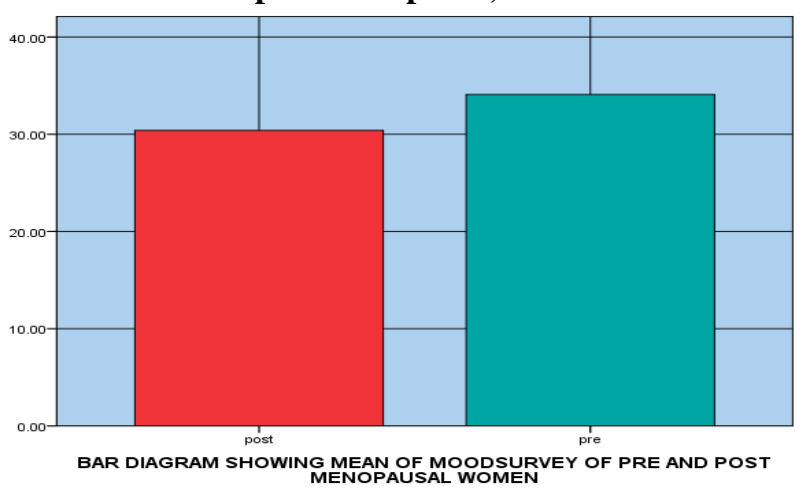

Pre-menopause: middle age

Post menopause: old age 
Figure1.2: Showing mean of self esteem of middle age women (pre-menopause) and old age women( post menopause)

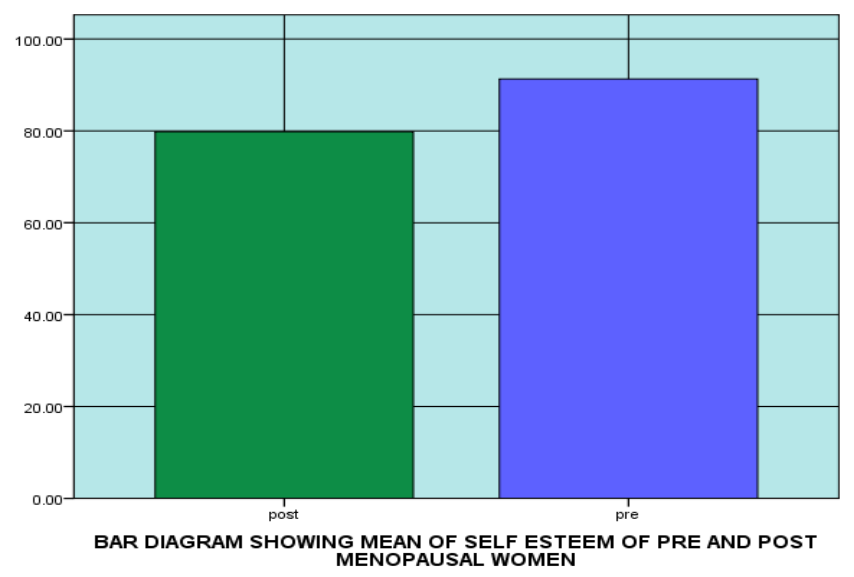

Pre-menopause: middle age

Post menopause: old age

Figure1.3: Showing mean of body image of middle age women ( pre-menopause) and old age women (post menopause)

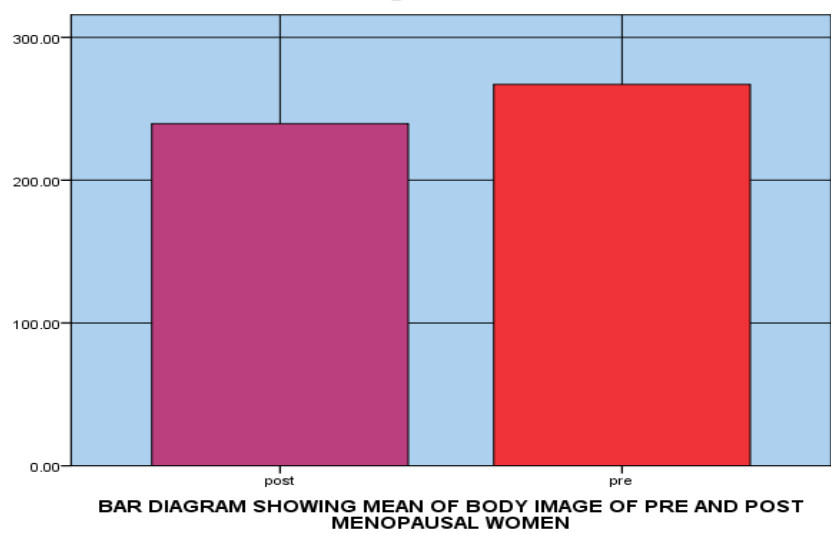

Pre-menopause: middle age

Post menopause: old age

\section{Discussion}

The results obtained from the $t$ test calculated on the 3 scales(MBSRQ, MS and SERS)in middle age women (pre-menopausal state) and old age women (post-menopausal state) showed a significant difference in Body self image as shown in table 1.2, in moods shown in table 1.3 and the level of self esteem as shown in table 1.4. The mean of Body image in Middle age women is $\mathrm{M}=2.6708 \mathrm{SD}=26.81808$ is higher than that of Old age women $\mathrm{M}=2.3952 \mathrm{SD}=29.45624$ as shown in table 1.1.The mean of Mood in middle age women is $\mathrm{M}=34.0875 \mathrm{SD}=6.91209$ which is higher than that of old age women $\mathrm{M}=30.4000 \mathrm{SD}=5.21585$ as shown in table 1.1.The mean of self esteem of middle age women $\mathrm{M}=91.3000 \mathrm{SD}=8.96463$ is higher than that of the old age women $\mathrm{M}=79.8000 \mathrm{SD}=12.42333$ as depicted in table 1.1

Thus, our first hypothesis : "There is a significant difference between the old age woman and middle age woman in terms of Body Self image, moods and self esteem" is accepted.

This is because of the fact that ageing impacts the two groups of women( middle age and old age ) in different manner. The results obtained shows that Ageing as perceived by a middle age women can be distinct from that of an old age women. The middle age women were in their peak of youth along with being in a premenopausal state. The pre-menopausal phase is a transition phase for women as she undergoes a lot of hormonal changes which is accompanied by various physiological and psychological symptoms. The old age women were in their post-menopausal state. The old age women were out of the menstrual related issues and lead a more comfortable life in terms of the hormonal balance. The old age women have a different outlook towards life as compared to the middle age women in context to the Indian culture. This difference in the developmental phase along with the influence of culture brings about a significant difference in the level of Body self image, moods and self esteem in both groups of women 
The one way ANOVA as depicted in table1.5 shows significant results between the 2 groups. The statistical analysis shows that the middle age women has a higher level of body self image, moods and self esteem as compared to the old age women.

Our second Hypothesis, "The old age woman have higher Body self image, moods and self esteem as compared to the middle age woman "is thus rejected. The present study was conducted on Indian women of middle class homes. Most respondents who belonged to the old age were found to be more concerned about their appearance, sexuality and changes in their moods and body, thereby affecting the self esteem. This Phenomenon was much similar to the Western societies for whom menopause represents a challenging and difficult period. The perceived loss of youth and beauty at menopause indicated a major embarrassment for them. Crossing of this imagined doorway into old age was a measure of stumbling block for many (Bachmann 1994).Studies have affirmed that appearance-related menopausal concerns may be especially strong for those women who objectify their bodies as prescribed by the cultural context that defines women in terms of their appearance (McKinleyand Hyde1996). Having negative attitudes towards menopause or anxiety about aging may increase this sort of objectification (McKinley and Lyon 2008). Though the culture of India is very different from the Western culture, and according to the phases of life as given by India's ancient law giver Manu in his Dharmashahtra, women along with men accepts ageing very calmly after the marriage of the children. But the researcher would like to argue that in today's cosmopolitan culture of urban India; an individual's circumstances, desires, day to day experiences and perceptions may provide the respondents a ground to associate menopause with loss of femininity. Many Indian Woman believe that monthly menstrual bleeding would clean their body of 'dirty blood'. As this process was discontinued at menopause they believed that they have grown physically weak, lost interest and enthusiasm. They felt that their importance had decreased and that they were of no use. Thus many times they associated menopause with loss of femininity. This can further thought to be interfering with their confidence and self-image and self-esteem. Decreased physical capacity, loss of interest from social life, loss of sexual interests, loss of stamina, feeling of being old, feeling depressed was associated with menopause. (Arti Kaulagar ,"Menopause and Femininity: Qualitative Enquiry into Menopause of Urban Women from Pune, Maharashtra 2010). The results obtained from the present study hereby proves that the old age women(post menopause) of urban India has a low Body self image, moods and self esteem as compared to the middle age women. Today, an urban Indian old women is seen to be highly concerned with ageing more than the middle age women as they want to keep pace with the youth oriented patriarchal society. As mentioned earlier by the researcher in India a women plays a major role but as she ages her daughter in laws which she so fondly marries her son to is found to slip into her position forcing her to take a back seat. This, along with her menopause makes her feel unwanted and less feminine as compared to the younger women of her family. A women hates to lose her importance in the eyes of her own family members and this may be another reason for the achieved results of the present research which showed that old age women have a lower bodyself image, moods and self esteem as compared to the middle age women. The respondents of the middle age group were from the age group 40-55years.During this age range a women is at her epitome of youth as she slowly faces the perimenopausal symptoms. Majority of the respondents of this age group in the present study experienced premenopause as a normal process of aging rather than as disease or loss of womanhood, femininity. For majority of the respondents, menopause found to be a process consisting of physical and hormonal changes in women's body happening alongside changes associated with ageing in general, and changes in women's family and social life. These changes were easily acceptable as they were considered as a constructed part of society, which have been carried forward from generations to the present. For them, menopause indicated end of the childbearing years and for many women it was associated with end of years of raising children.

Most of the respondents of the above study had adolescent children and their rearing work with regards to the younger women with younger children were less. This itself ushered in a sense of freedom to the middle age women and they were able to concentrate more time on their own self in all ways. Although the Western culture views midlife women's body weight and associated changes in the appearance as unattractive, not all women draw on that definition of femininity in Indian culture. Instead, many in this study provided a more relevant explanation of femininity that is defined by independence, self-acceptance and self-reliance. In India, at this age a women wants to live her life to her fullest and enjoy her youthful beauty Mostly, in India by the age of 40 women have completed the child bearing work and with grown up children, she finds more time for her husband and is seen to enjoy life more fully. Most Indian women starts concentrating on her sex life more at this age as she finds more time for herself. In India as soon as a women marries she is burdened with not only looking after her husband but also his entire family along with bearing and rearing a child . These activities leaves her with very less time but as she grows in age she is able to handle her responsibilities better as well as squeeze out more time for herself .Most respondents claimed to have a more satisfied sexual life, as reported in the rapport formation stage which is a good reason for her high scores in terms of bodyself image, moods and 
self esteem. Women have been reported to appreciate menopause in developing countries and especially in India (Flint and Samil 1990; Singh and Arora 2005; Gupta et al. 2006).

The third hypotheses, "Body self image, moods and self esteem in both age group of woman will have a positive correlation" is partially accepted on the basis of the results obtained . A positive correlation between the three variables are seen in case of the Old age women as shown in table 1.6 but no correlation was seen in case of the middle age women as shown in table 1.7. This is because those respondents from the old age group showed an even trend in their responses and the raw scores revealed in most cases that if there was a low score in body self image it led to a low score in the moods and thus leading to a low Self esteem. This was because those ageing women who were undergoing the post menopausal issues of losing feminity were directly affected in their body self image ,moods and their self esteem. Even in context to the Indian culture they were unable to adjust to their changing position in the family, so was dearly affected in their self esteem and moods...But it was not so in case of the middle age women as no correlation was seen in between the variables. Some women showed a high score in self esteem which could not be related to either body-self image or moods. The respondents belonging to the middle age were taken from the age group 40-55 years which marked the epitome of youth hood along with the perimenopausal symptoms. The researcher would state that the study aimed at studying whether ageing had an impact on the body self image, moods and self esteem in middle age women and old age women so taking middle age women from 40years onwards was vital as 40 begins the onset of middle age which in modern period continues till around 50plus.At this age a women may have a high self esteem which may not be directly related to a high Body self image, but it can be because of other factors like a good job, good education, caring husband etc. Moreover, higher level of mood may be because of the desire of a middle age women to live life to the fullest after the initial stress of marital life and child rearing. Her ability to finally find more time for herself and enjoy a good sex life may be the reason of her high mood even though she may not have a high body self image. Similarly her self esteem may not be directly related to either moods or body self image. During the rapport formation it was noted that even though some respondents did not have a high Body self image but in no way it affected their mood or their self esteem as the increasing number of years with her husband had ushered in more confidence in her own self. This may be the reason for the results which show that in middle age there is no correlation amongst the 3 variables, body self image, moods and self esteem.. While reviewing each individual score it was also seen that the more than majority of the middle age women were in between 40-55 were aware and could handle their peri-menopausal symptoms much better so in a way their scores were not affected by ageing. Their middle age was only a strong reason for her high self esteem, even though she did undergo some low moods because of the perimenopausal symptoms. This is because a middle age women in India is in a better role than an ageing women as at middle age after gaining years of experience in marriage, she is able to handle all her marital duties from looking after her husband, children and in laws she also becomes a controlling figure as her ageing mother in law retires. This itself raises her self esteem and uplifts her moods even though biologically she may be undergoing peri-menopausal symptoms. The results of the present research also reveals how ageing is not only influenced by the biological changes but it is today greatly impacted by the culture and society.

\section{Conclusion}

The present study explored the effect of Ageing on Body self image, moods, and self esteem in middle age women and old age women. It was apparent from the study that in India Ageing is not only influenced by biological changes but to a great extent by the culture and society. This major finding was concluded on the basis of the achieved results which depicted that the middle age women who biologically are in more of a crisis period because of the perimenopausal symptoms is less affected by ageing in their body self image ,moods and self esteem in comparison to the old age women who were in their post menopausal phase with a more balanced hormonal state. The old age women in India were having a low body image, a low self esteem and a low mood because of the cultural influence which forces them to feel unwanted and less feminine. This brings in a lot of similarity of the urban Indian old age women with the western old age women though culturally they are very distinct from each other. The culture of the cosmopolitan urban India is making higher demands on the old age women rather than the middle age women. More so, the present middle age women are getting immense support from the world of medical science to fight ageing thus are able to carry a better body self image. They are able to deal with the midlife crisis more successfully leading to a high mood and greater self esteem. Another, finding is that in case of the old age women or the post menopausal women, there was a positive correlation between body self image, moods and self esteem. Their low body self image was because they felt a less feminine after undergoing menopause which led to a low mood with the feelings of being unwanted as most of her important jobs of bearing and rearing children are over. This was a blow to their self esteem. Whereas, no correlation was seen in body self image, moods and self esteem in case of the middle age women, as they were not dearly affected by ageing and their certain high moods or high self esteem can be related to other issues like good job, higher education, higher position in the family rather than a direct relation to body self image. Thus, 
it can be concluded that a mid life is no longer a crisis for a women in India rather it is a phase where a women finally breathes freedom to enjoy a more fuller life. It can be further believed that soon ageing an unavoidable phase of human life, will be dealt more positively. Every ageing women will take the challenges of perimenopausal and post menopausal phase with good vigyor be it physically, psychologically and socially.

Robert Browning has very appropriately summed up his feelings in the memorable lines

"Grow old along with me!

The best is yet to be,

The last of life for which the first was made".

\section{References}

[1]. Flint, M, Samil, R.S. (1990). Cultural and subcultural meanings of the menopause. Ann N Y Acad Sci, 592: 134-148

[2]. Gupta, P., Sturdee, D.W., \& Hunter, M.S (2006). Mid-age health in women from the Indian subcontinent (MAHWIS):general health and the experience of menopause in women. Climacteric, 9: 13-22.

[3]. Lock. M (2002). Symptom reporting at menopause: a review of cross-cultural findings. J Br Menopause Soc, 8(4):132-136

[4]. McKinley, N. M., \& Hyde, J. S. (1996). The objectified body consciousness scale: Development and validation. Psychology of Women Quarterly, 20, 181-215.

[5]. McKinley, N.M., \& Lyon, L.A.(2008). Menopausal attitudes, objectified body consciousness, aging anxiety, and body esteem: European American women's body experiences in midlife. Body Image, 5: 375-380

[6]. Singh, A., Arora, A.K (2000). Menopausal women's profile in rural North India - an integrated qualitative and qualitative study. Adv Obstet Gynecol, 52: 309-313.

[7]. Scanzoni.L ,Scanzoni. L.H,(1988). Men, women, and change: sociology of marriage and family. McGraw-Hill.The University of Michigan 